\title{
Heat Tolerance of Five Taxa of Birch (Betula): Physiological Responses to Supraoptimal Leaf Temperatures
}

\author{
Thomas G. Ranney \\ Department of Horticultural Science, Mountain Horticultural Crops Research and Extension Center, \\ North Carolina State University, 2016 Fanning Bridge Road, Fletcher, NC 28732-9216 \\ Mary M. Peet \\ Department of Horticultural Science, North Carolina State University, Raleigh, NC 27695-7609
}

Additional index words. Betula nigra, Betula papyrifera, Betula pendula, Betula platyphylla var. japonica, Betula jacquemontii, carbon exchange rate, chlorophyll fluorescence, gas exchange, high temperatures, photosynthesis, quenching, respiration

\begin{abstract}
Leaf gas-exchange and chlorophyll fluorescence measurements were used as indexes for evaluating heat tolerance among five taxa of birch: paper (Betula papyrifera Marsh.), European (B. pendula Roth.), Japanese (B. platyphylla var. japonica Hara. cv. Whitespire), Himalayan (B. jacquemontii Spach.), and river (B. nigra L. cv. Heritage). Gas-exchange measurements were conducted on individual leaves at temperatures ranging from 25 to $40 \mathrm{C}$. River birch maintained the highest net photosynthetic rates $\left(P_{n}\right)$ at high temperatures, while $P_{n}$ of paper birch was reduced the most. Further study of river and paper birch indicated that the reduced $P_{n}$ at high temperatures and the differential sensitivity between taxa resulted from several factors. Inhibition of $P_{n}$ at higher temperatures was due largely to nonstomatal limitations for both taxa. Increases in respiration rates, decreases in maximal photochemical efficiency of photosystem (PS) II $\left(F_{\mathrm{v}} / F_{\mathrm{M}}\right)$, and possible reductions in light energy directed to PS II ( $F_{0}$ quenching) were apparent for both taxa. The capacity of river birch to maintain greater $P_{n}$ at higher temperatures seemed to result from a lower $Q_{10}$ for dark respiration and possibly greater thermotolerance of the Calvin cycle as indicated by a lack of nonphotochemical fluorescence quenching with increasing temperatures. Thermal injury, as indicated by a rapid increase in minimal, dark-acclimated $\left(F_{0}\right)$ fluorescence, was not evident for either paper or river birch until temperatures reached $\approx \mathbf{4 9 C}$ and was similar for both taxa.
\end{abstract}

Heat stress can be a principal limiting factor in the distribution, adaptability, and productivity of wild and cultivated plants. Inhibition of growth or plant decline under supraoptimal temperatures can result from thermal effects on many physiological and developmental processes (Fitter and Hay, 1987). Net photosynthesis $\left(\mathrm{P}_{\mathrm{n}}\right)$, in particular, is one of the most heat-sensitive processes that governs plant growth (Björkman et al., 1980). Consequently, physiological adaptation of $\mathrm{P}_{n}$ processes to high temperatures and maintenance of $P_{n}$ under supraoptimal temperatures is often a key factor in the adaptability of plants to high temperatures. The optimal temperature range for $\mathrm{P}_{\mathrm{n}}$ is usually correlated with the temperature optimum for plant growth, and both optima are typically reflective of the plant's native (evolutional origin) climate (Berry and Björkman, 1980; Björkman et al., 1980; Fryer and Ledig, 1972; Larcher, 1991; Pisek et al., 1973). As a result, studying the sensitivity of $\mathrm{P}_{\mathrm{n}}$ to high temperatures can serve as an integrated measure and effective tool for evaluating and comparing plant adaptability to warm environments.

There is considerable variation in the thermotolerance of $\mathrm{P}_{\mathrm{n}}$ among plants of different genera (Björkman et al., 1980), species (Hällgren, et al., 1982; Koike and Sakagami, 1985), and in some cases ecotypes and provenances (Fryer and Ledig, 1972; Tesfai et

\footnotetext{
Received for publication 15 Jan. 1993. Accepted for publication 28 June 1993. The work reported in this publication was supported in part by the North Carolina Agricultural Research Service (NCARS), Raleigh; Evergreen Nursery, Co., Sturgeon Bay, Wis.; and Bracken Tree Growers, Jonesborough, Tenn. Use of trade names in this publication does not imply endorsement by the NCARS of products named nor criticism of similar ones not mentioned. We gratefully acknowledge the technical assistance of Everett Whitman and station personnel. The cost of publishing this paper was defrayed in part by the payment of page charges. Under postal regulations, this paper therefore must be hereby marked advertisement solely to indicate this fact.
}

al., 1991). For example, Koike and Sakagami (1985) found that Japanese birch, a species found on more exposed sites, was able to maintain net photosynthesis at higher temperatures (40C) than monarch birch (B. maximowicziana Regel.), a species typically found in valleys.

Changes in chlorophyll fluorescence can serve as an indicator of stress-induced limitations of photosynthesis and can provide insights into specific physiological components of photosynthesis that are sensitive to environmental stress (Bilger et al., 1987). Chlorophyll fluorescence characteristics have also proven useful in screening plants for heat tolerance (Bilger et al., 1984; Havaux et al., 1988; Hetherington et al., 1983; Moffatt et al., 1990). The use of pulse modulation fluorimetry, in particular, permits resolution of complicated fluorescence responses into photochemical and nonphotochemical components (Schreiber and Bilger, 1987).

Because many species of birch are important nursery or forestry crops, a greater understanding of the heat tolerance of different species and the specific characteristics and mechanisms that influence heat tolerance would aid in evaluating, selecting, and improving birches for different climates.

The objectives of this project were to 1) compare responses of $P_{n}$ to supraoptimal temperatures among five taxa of birch;2) identify taxa more tolerant of high temperatures as indicated by a greater capacity to maintain photosynthesis under high temperature stress; and 3) study mechanisms contributing to variation in response of $\mathrm{P}_{\mathrm{n}}$ to supraoptimal temperatures.

\section{Materials and Methods}

Plant material and handling. Five taxa of birch were grown and studied: 'Heritage' river birch, paper birch, European white birch, Himalayan birch, and 'Whitespire' Japanese birch. Trees were 
grown outdoors in 19-liter containers on a gravel bed located at the Mountain Horticultural Crops Research Station, Fletcher, N.C. The container media consisted of milled pine bark $(<13 \mathrm{~mm})$ amended with 3.0 and $0.89 \mathrm{~kg}$ of dolomitic limestone and micronutrient fertilizer (Micromax, Grace Sierra Horticultural Products Co., Milpitas, Calif.) $/ \mathrm{m}^{3}$, respectively. Twenty eight grams of 18N-2.6P-10K slow-release fertilizer (Osmocote; Grace Sierra, Milpitas, Calif.) was surface-applied to each container in April 1991. Plants were irrigated with $\approx 7.6$ liters of water each day by drip irrigation. Trees were 4 years old, typically multistemmed, and 1.0 to $1.2 \mathrm{~m}$ high. Plants were arranged in a completely randomized design with six replicate trees per taxon.

Leaf gas exchange. Gas exchange was measured on individual, attached leaves using an open-flow gas-exchange measurement system. This system consisted of a temperature-controlled cuvette (model DDG-9920, Data Design Group, LaJolla, Calif.) regulated with a temperature controller (model CN-9000, Omega Engineering, Stamford, Conn.), a $\mathrm{CO}_{2}$ analyzer and flowmeter (model LI-6250, LI-COR, Lincoln, Neb.) configured for open flow, and a data logger (model LI-6200, LI-COR). Leaf temperature was measured using a leaf temperature thermocouple (model 6000TC, LI-COR). A system of solenoid valves (Clippard Instrument Lab, Cincinnati) and an additional temperature-relative humidity sensor (Data Design Group) were configured such that part of the incoming air stream could be diverted and routed through the additional sensor and the $\mathrm{CO}_{2}$ analyzer to verify the incoming $\mathrm{CO}_{2}$ and vapor pressure before it entered the cuvette. The $\mathrm{CO}_{2}$ concentration in the cuvette was maintained at a mean of $342 \mathrm{ppm}(6 \mathrm{SD})$ by blending (ADC gas mixer, Hoddesdon, U.K.) incoming air from two tanks with varying $\mathrm{CO}_{2}$ concentrations (each with $21 \%$ $\mathrm{O}_{2}$ and the balance $\mathrm{N}_{2}$ ). The vapor-pressure deficit of the incoming air was controlled for each measurement by regulating the proportion of the air stream that was bubbled through water in an Erlenmeyer flask heated to 50C. The air inside the cuvette was maintained at a mean vapor-pressure deficit of $1.34 \mathrm{kPa}(0.22 \mathrm{SD})$ for gas-exchange measurements over all temperatures. Artificial light was provided with a quartz filament lamp providing an irradiance of $1200 \mu \mathrm{mol} \cdot \mathrm{m}^{-2} \cdot \mathrm{s}^{-1}$ photosynthetically active radiation (PAR) at the leaf surface.

Individual plants were carefully brought indoors immediately before being measured. One leaf, the third to fifth most recently matured (late-formed), was situated inside the cuvette and allowed to acclimate for $20 \mathrm{~min}$ at $25 \mathrm{C}$ before the first measurement. The leaf temperature was then increased $5 \mathrm{C}$ at $\approx 1 \mathrm{C} / \mathrm{min}$, the leaf was allowed to acclimate for $20 \mathrm{~min}$, and the next measurement was taken. This procedure was repeated until measurements had been taken at leaf temperatures of 25, 30, 35, and 40C. All plants were well watered when measured.

Dark respiration rates were measured during daylight hours for the two species (river and paper birch) that showed the greatest differences in photosynthesis at higher temperatures. The same protocol and gas-exchange measurement system was used as described for measuring leaf gas exchange in the light, except that the leaf cuvette was enclosed in aluminum foil to exclude light.

Gas-exchange measurements were conducted from 26 July to 19 Aug. 1992. During this period, the mean daily and mean daily high temperatures outdoors were 21.9 and 26.6C, respectively. Equations for calculating $\mathrm{P}_{\mathrm{n}}$, stomatal conductance $\left(\mathrm{g}_{\mathrm{s}}\right)$, and concentration of internal leaf $\mathrm{CO}_{2}\left(\mathrm{C}_{\mathrm{i}}\right)$ followed the procedure of von Caemmerer and Farquhar (1981).

Chlorophyll fluorescence measurements. Fluorescence measurements were conducted at room temperature (20 to 22C) using a pulse modulation chlorophyll fluorometer (model PAM 101,
Walz, Effeltrich, Germany). Terms and symbols used in discussing these measurements are consistent with nomenclature presented by van Kooten and Snel (1990).

Fluorescence measurements were conducted on intact leaves of paper and river birches enclosed in a temperature-controlled cuvette (described previously) with compressed air $\left(\mathrm{CO}_{2}=350 \mathrm{ppm}\right)$ supplied at a flow rate of 1 liter $\cdot \mathrm{min}^{-1}$. Minimal, dark-acclimated fluorescence $\left(F_{0}\right)$ was determined while applying a pulsed light at a frequency of $1.6 \mathrm{kHz}$. Maximum, dark-acclimated fluorescence $\left(F_{\mathrm{M}}\right)$ was determined with an additional saturating flash of white light at $2500 \mu \mathrm{mol} \cdot \mathrm{m}^{-2} \cdot \mathrm{s}^{-1} \mathrm{PAR}$ for $0.8 \mathrm{sec}$. Maximal variable fluorescence of dark-acclimated samples $\left(F_{\mathrm{v}}\right)$ were calculated as $F_{\mathrm{M}}-F_{0}$. Leaf temperature was adjusted and regulated as described for the gasexchange measurements. Leaves were acclimated in the dark for 20 $\min$ at a given temperature before each measurement.

Photochemical quenching $\left(q_{\mathrm{P}}\right)$, nonphotochemical quenching $\left(q_{\mathrm{N}}\right)$, and minimal fluorescence quenching $\left(q_{0}\right)$ were measured on separate leaves at 25 and 40C. After the samples were preconditioned in the dark for $20 \mathrm{~min}, \mathrm{~F}_{0}$ and $F_{\mathrm{M}}$ were measured as described above. Following complete relaxation of fluorescence from the initial light flash, a fluorescence kinetic was induced with actinic white light at $275 \mu \mathrm{mol} \cdot \mathrm{m}^{-2} \cdot \mathrm{s}^{-1}$. Supplemental saturating flashes of white light $\left(2500 \mu \mathrm{mol} \cdot \mathrm{m}^{-2} \cdot \mathrm{s}^{-1}\right)$ were applied every $20 \mathrm{sec}$. After 12 min, the actinic light and saturating flashes were turned off and the subsequent light-acclimated, minimal fluorescence $\left(\mathrm{F}_{0}{ }^{\prime}\right)$ was determined. Quenching coefficients were calculated according to Bilger and Schreiber (1986). Values of $q_{\mathrm{P}}$ and $q_{\mathrm{N}}$ were determined at $10 \mathrm{~min}$ following illumination of the leaf with actinic light.

Dark-acclimated fluorescence was also measured over a range of 25 to $60 \mathrm{C}$. Temperatures were increased at $\approx 1 \mathrm{C} / \mathrm{min}$. Measurements were taken using a pulsed measuring light at a frequency of $1.6 \mathrm{kHz}$.

Gas-exchange and fluorescence measurements were blocked over time with complete blocks consisting of one tree of each species measured in random order. Complete blocks were measured on a given day. Analysis of variance and regression analyses were conducted using SAS's general linear model procedure (SAS Institute, Cary, N.C.). Simple linear or quadratic polynomial curves were fit to the data when significant trends were identified in the regression analyses.

\section{Results}

Leaf gas exchange. Absolute and relative (percentage of maximum) $\mathrm{P}_{\mathrm{n}}$ decreased quadratically with increasing temperatures for all taxa (Fig. $1 \mathrm{~A}$ and $\mathrm{B}$ ). A significant taxon $\times$ temperature (quadratic) interaction demonstrated that, as temperatures increased, the rate of decrease in $\mathrm{P}_{\mathrm{n}}$ varied by taxon for absolute and relative measurements. Net photosynthesis of river birch was least affected and $\mathrm{P}_{n}$ of paper birch was most affected by increasing temperatures. At 40C, there was also considerable variation in absolute and relative $\mathrm{P}_{n}$ among taxa. River birch maintained the highest absolute and relative $\mathrm{P}_{n}$ (58\% of maximum), while $\mathrm{P}_{\mathrm{n}}$ of paper birch were the lowest (28\% of maximum) when evaluated at 40C. Paper birch was also the only taxon that significantly decreased in relative $\mathrm{P}_{\mathrm{n}}$ as temperatures increased from 25 to $30 \mathrm{C}$.

Stomatal conductance was affected by a significant temperature (linear) $\times$ taxon interaction. As temperatures increased, $g_{s}$ decreased linearly for all taxa, except river birch, which had an increase in $g_{\text {s }}$ with increasing temperature (Fig. 2A). When compared at $40 \mathrm{C}, \mathrm{g}_{\mathrm{s}}$ of river birch was significantly higher than $g_{s}$ of the other taxa.

Calculated $\mathrm{C}_{\mathrm{i}}$ increased with increasing temperature for all taxa 

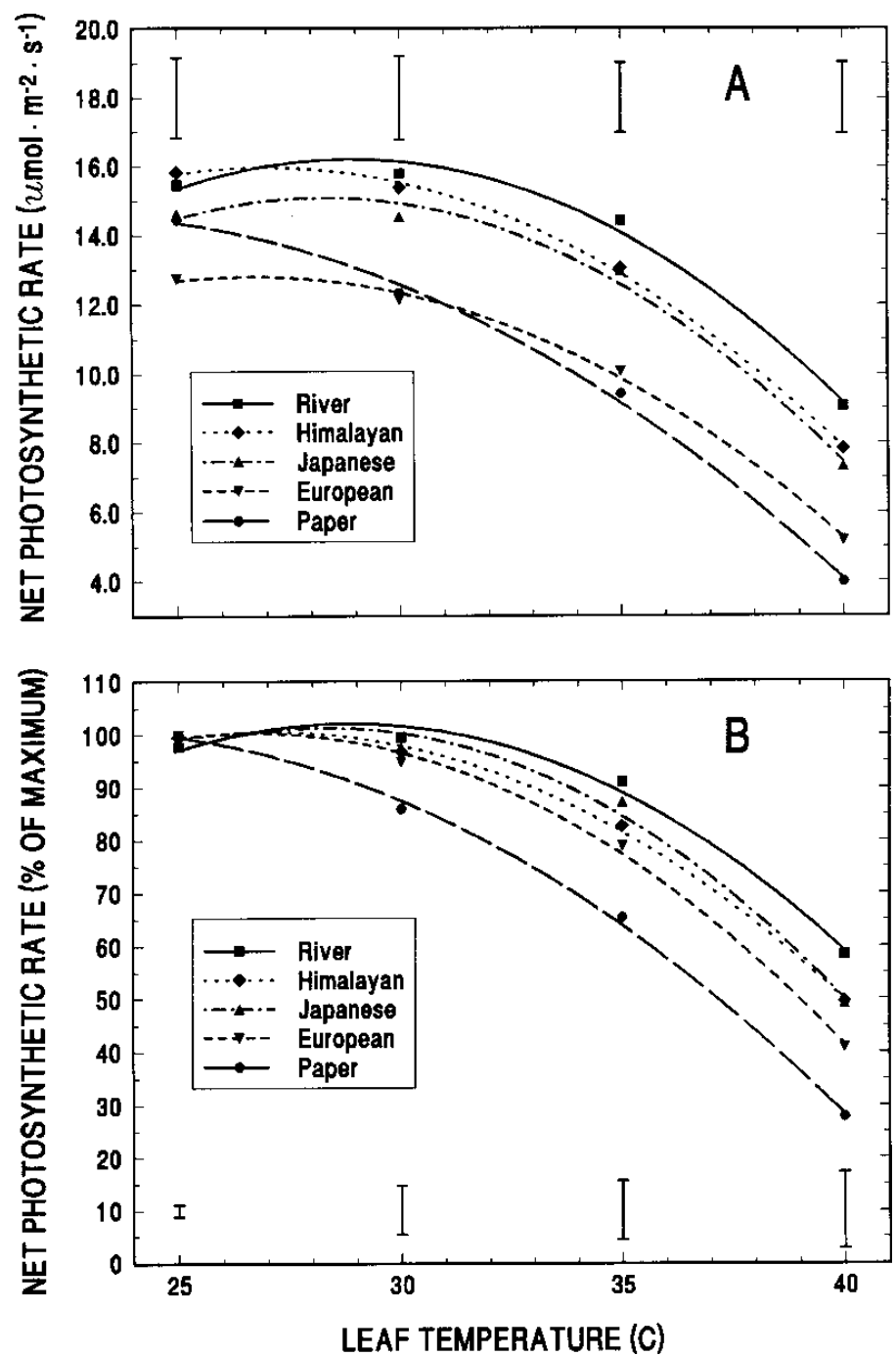

Fig. 1. Absolute (A) and relative (B) net photosynthetic rates of five taxa of birch in response to increasing temperatures. Measurements were conducted on individual leaves after first acclimating to $25,30,35$, or $40 \mathrm{C}$ for $20 \mathrm{~min}$. Lines represent predicted values based on polynomial (quadratic) regression analysis. Data points represent means, with $\mathrm{n}=6$. Vertical bars represent $\mathrm{LSD}_{0.05}$ among taxa at a given temperature.

(Fig. 2B). There was also a significant difference in $\mathrm{C}_{\mathrm{i}}$ among taxa. Main-effect means for $\mathrm{C}_{\mathrm{i}}$ averaged over all temperatures were 237 , 224, 223, 217, and 202 ppm for river, Japanese, European, Himalayan, and paper birch, respectively, with a least significant difference $(P \leq 0.05)$ of 22 . There was no significant taxon $\times$ temperature interaction effect on $\mathrm{C}_{i}$.

Dark respiration rates increased linearly with increasing temperature, but at different rates for paper and river birches as indicated by a significant taxon $\times$ temperature interaction (Fig. 3 ). Although paper and river birches had similar dark respiration rates at $25 \mathrm{C}$, dark respiration rates of paper birch increased at more than twice the rate of those of river birch with increasing temperatures. Temperature coefficients $\left(\mathrm{Q}_{10}\right)$ for dark respiration (rate at $\mathrm{t}+$ $10 \mathrm{C}) /($ rate at $\mathrm{tC}$ ) were 1.78 and 1.37 for paper and river birch, respectively. Because paper and river birches have similar dark respiration rates at $25 \mathrm{C}$, data showed similar trends when presented on a relative basis, regardless of whether the data are expressed per unit area or per unit weight.

Chlorophyll fluorescence. As leaf temperatures increased from 25 to $40 \mathrm{C}, F_{0}$ increased with a gradual, but significant, linear trend for both taxa (Fig. 4A). There was no significant difference in $F_{0}$
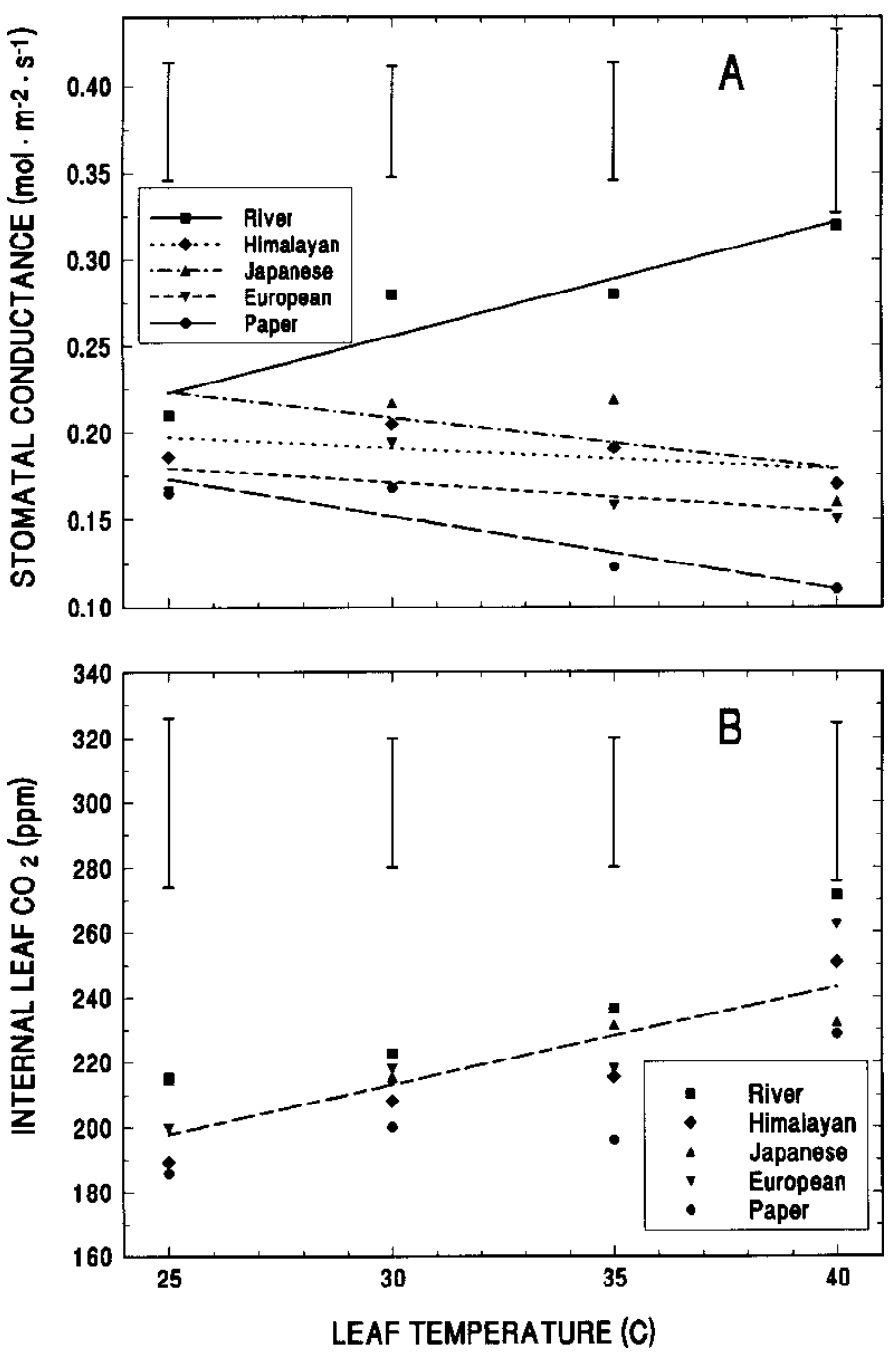

Fig. 2. Stomatal conductance $(\mathbf{A})$ and internal leaf $\mathrm{CO}_{2}(\mathbf{B})$ of five taxa of birch in response to increasing temperatures. Measurements were conducted on individual, intact leaves after acclimating to $25,30,35$, or $40 \mathrm{C}$ for $20 \mathrm{~min}$. Lines represent predicted values based on linear regression analysis. Data points represent means, with $\mathrm{n}=6$. Vertical bars represent $\mathrm{LSD}_{0.05}$ among taxa at a given temperature.

between taxa (main effect) and no taxon $\times$ temperature interaction. Maximal variable fluorescence $\left(F_{\mathrm{v}}\right)$ decreased quadratically, with no difference between taxa (main effect) and no taxon $\times$ temperature interaction. The ratio of $F_{\mathrm{v}} / F_{\mathrm{M}}$ also decreased in a significant curvilinear fashion with no difference between taxa (main effect) and no taxon $\times$ temperature interaction (Fig. $4 \mathrm{~B}$ ).

Analysis of quenching coefficients showed that $q_{\mathrm{P}}$ did not differ between taxa (main effect), was not influenced by temperature (linear regression analysis), and was not influenced by taxon $\times$ temperature interactions (Fig. 5A). In contrast, there was a temperature $\times$ taxon interaction on $q_{\mathrm{N}}$. As temperatures increased from 25 to $40 \mathrm{C}, q_{\mathrm{N}}$ increased for paper birch and decreased for river birch. Quenching of minimal fluorescence $\left(q_{0}\right)$ increased in a similar linear trend for both taxa (Fig. 5B). There was no difference in $q_{0}$ between taxa (main effect) and no significant taxon $\times$ temperature interaction.

Analysis of $F_{0}$ over a range of temperatures from 25 to $60 \mathrm{C}$ (Fig. 6) showed a gradual increase in $F_{0}$ between 25 and $40 \mathrm{C}$ followed by a sigmoidal increase in $F_{0}$ with an inflection point $\left(\mathrm{T}_{\mathrm{C}}\right)$ near $49 \mathrm{C}$. There was no significant difference in $F_{0}$ between taxa at any of the measured temperatures. 


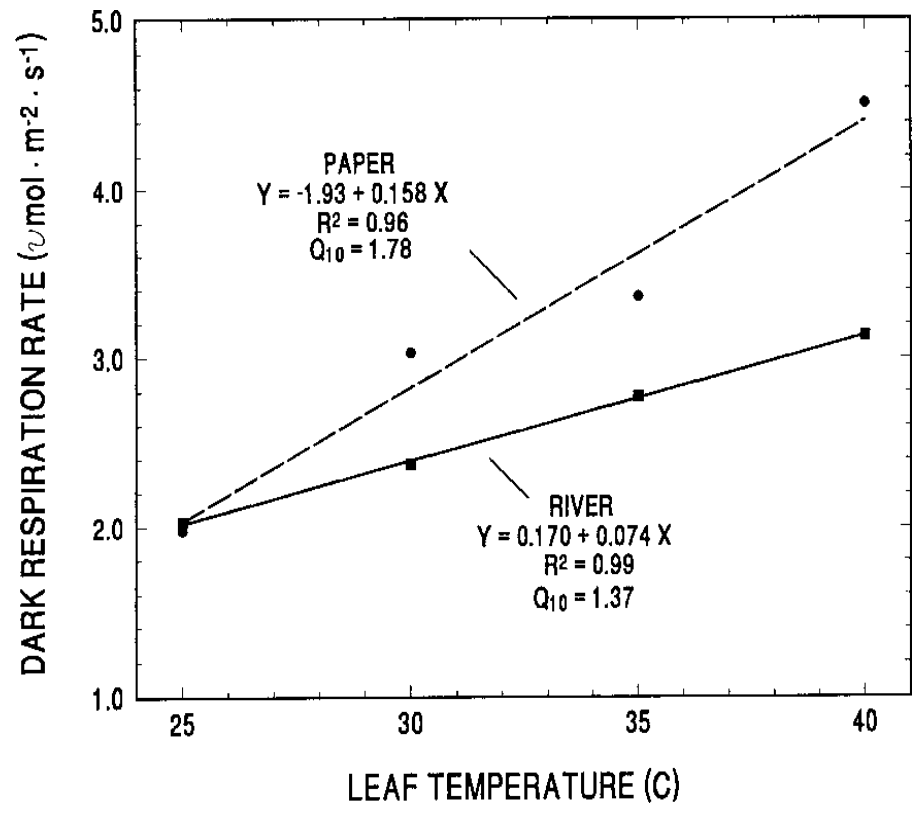

Fig. 3. Dark respiration rates as a function of increasing leaf temperature for paper and river birches. Measurements were conducted on individual, intact leaves after acclimating to $25,30,35$, or $40 \mathrm{C}$ for $20 \mathrm{~min}$. Data points represent means, with $\mathrm{n}=6$. Lines represent predicted values based on linear regression analysis.
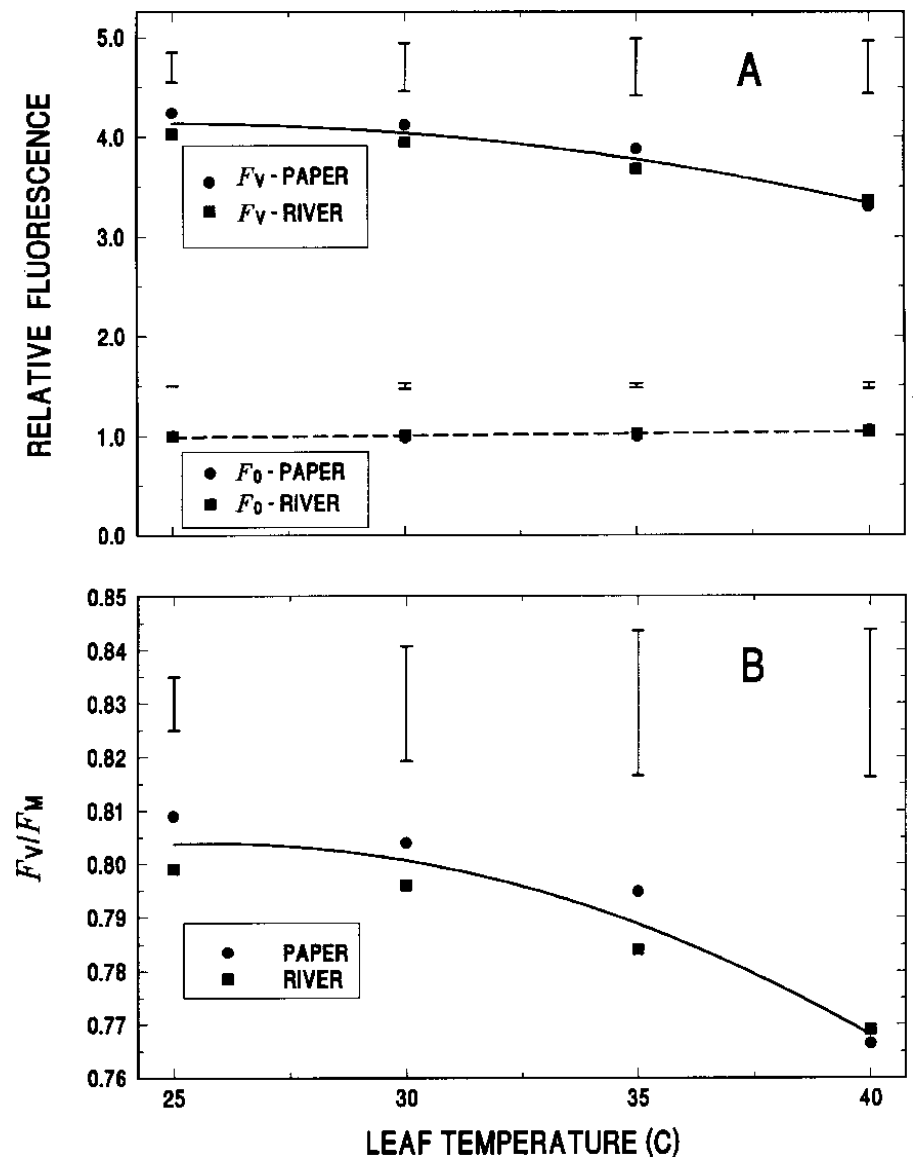

Fig. 4. Maximal variable fluorescence $\left(F_{\mathrm{V}}\right)$ and minimal, dark-acclimated fluorescence $\left(F_{0}\right)(\mathbf{A})$ and maximal photochemical yield of photosystem II $\left(F_{\mathrm{v}} /\right.$ $\left.F_{\mathrm{M}}\right)(\mathbf{B})$, for paper and river birch in response to increasing temperatures. Measurements were conducted on individual, intact leaves after acclimating to $25,30,35$, or $40 \mathrm{C}$ for $20 \mathrm{~min}$. Lines in both graphs represent the predicted response based on regression analysis. Data points represent means, with $\mathrm{n}=6$. Vertical bars represent $\mathrm{LSD}_{0.05}$ among taxa at a given temperature.
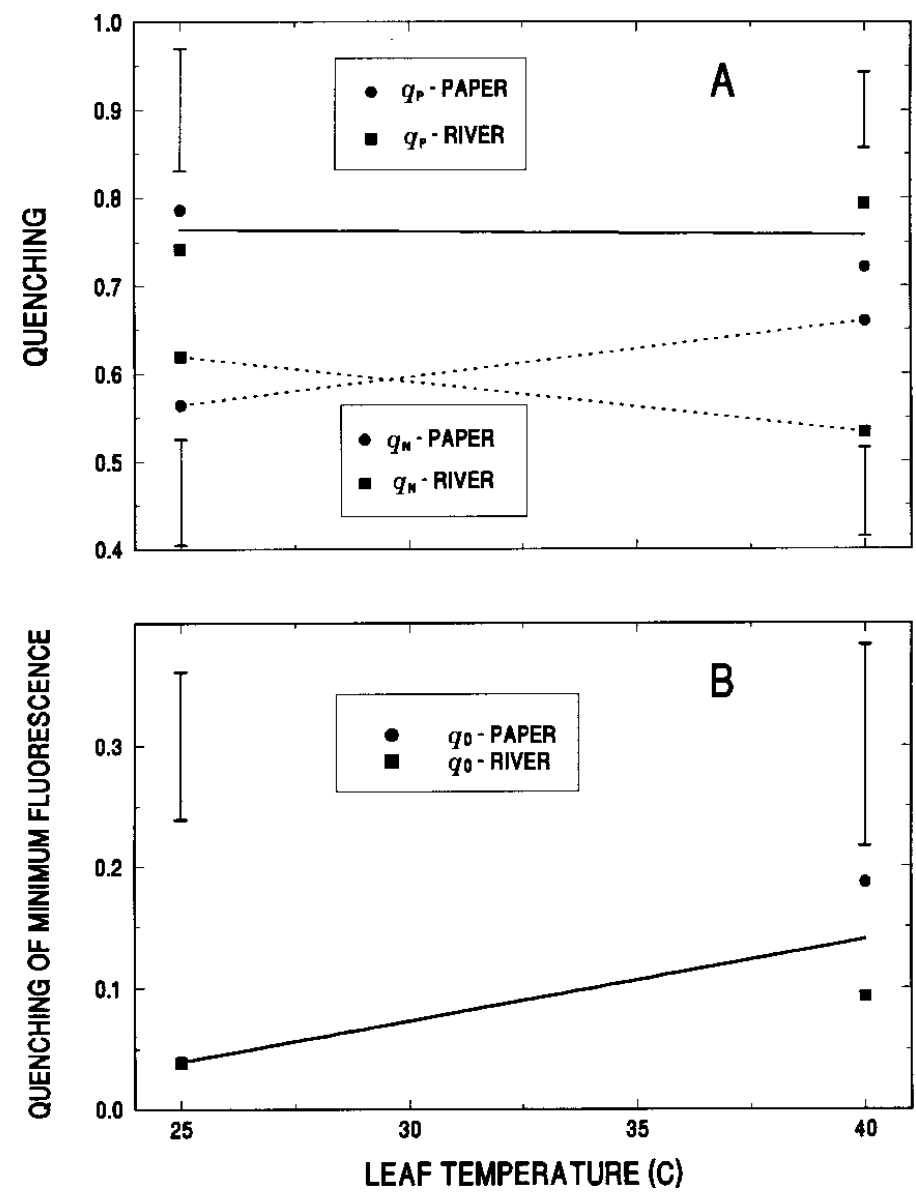

Fig. 5. Photochemical $\left(q_{\mathrm{p}}\right)$ and nonphotochemical $\left(q_{\mathrm{N}}\right)(\mathbf{A})$ and dark-level $\left(q_{0}\right)(\mathbf{B})$ fluorescence quenching for paper and river birch in response to increasing temperatures. Measurements were conducted on individual, intact leaves after acclimating to 25 or $40 \mathrm{C}$ for $20 \mathrm{~min}$. Lines connect mean values for $25 \mathrm{C}$ and $40 \mathrm{C}$. Data points represent means, with $\mathrm{n}=6$. Vertical bars represent $\mathrm{LSD}_{0.05}$ among taxa at a given temperature.

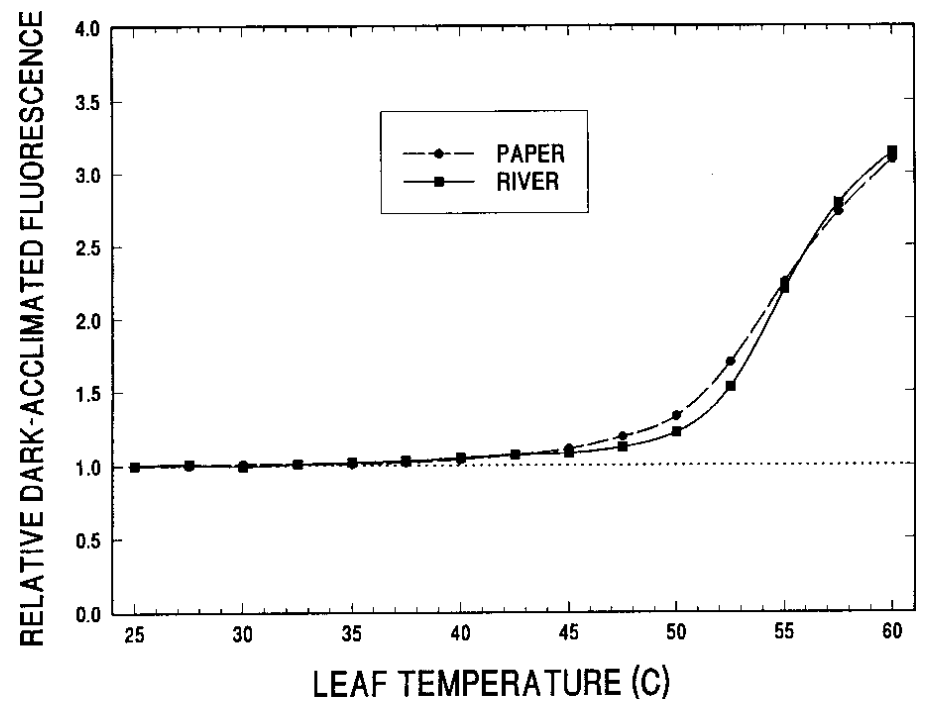

Fig. 6. Relative dark-acclimated fluorescence of paper and river birch in response to increasing temperatures. Measurements were conducted on individual, intact leaves with temperatures increasing from 25 to $60 \mathrm{C}$ at a rate of $\approx 1 \mathrm{C} / \mathrm{min}$. The critical temperature $\left(\mathrm{T}_{C}\right)$ resulting in a sudden rise in $\mathrm{F}_{0}$ was $\approx 49 \mathrm{C}$ for both species. Data points represent means, with $\mathrm{n}=6$. 


\section{Discussion}

Photosynthetic rates decreased substantially for most taxa as temperatures increased above 30C (Fig. $1 \mathrm{~A}$ and B). These results are similar to those reported by Koike and Sakagami (1985), who showed that photosynthetic rates of Japanese birch dropped considerably as temperatures increased in excess of $25 \mathrm{C}$ and ranged from $\approx 30 \%$ to $60 \%$ of maximum at a temperature of $40 \mathrm{C}$, depending on the time of year the response was measured. Differential sensitivity of $\mathrm{P}_{\mathrm{n}}$ to high temperatures was apparent among the five taxa (Fig. $1 \mathrm{~A}$ and B). Moreover, the capacity for certain taxa to maintain higher $\mathrm{P}_{\mathrm{n}}$ (absolute and relative rates) at increasing temperatures is consistent with differences in the natural ranges of these taxa (Ashburner and Schilling, 1985; Harlow et al., 1979; Krüssman, 1984; Liberty Hyde Bailey Hortorium, 1976). River, Himalayan, and Japanese birches, which were found to maintain higher rates of $\mathrm{P}_{\mathrm{n}}$ at supraoptimal temperatures, are native to more southern latitudes. In contrast, paper and European birches, which were found to have less ability to maintain $\mathrm{P}_{\mathrm{n}}$ at higher temperatures, are native to more northern latitudes. The differential capacity to maintain $\mathrm{P}_{\mathrm{n}}$ at high temperatures indicates that there is considerable variation in heat tolerance among birch species and that variations in the southernmost extent of the natural range seem to be related to tolerance of higher temperatures. Certainly, however, the possibility for intraspecific variation in heat tolerance within these species exists.

Although $\mathrm{g}_{\mathrm{s}}$ decreased at increasing leaf temperatures for several of the taxa studied, except river birch (Fig. 2A), $\mathrm{C}_{i}$ increased for all taxa (Fig. 2B). Increased $\mathrm{C}_{i}$ most likely resulted from increased respiration rates and decreased $P_{n}$ and further indicated that decreased $g_{s}$ is not responsible for decreasing $P_{n}$ at high temperatures. The increase in $\mathrm{g}_{\mathrm{s}}$ at higher temperatures observed for river birch was unique among the taxa studied but has been reported for a number of other plants (Even-Chen et al., 1981; Pearcy, 1977; Schulze et al., 1974). Although $g_{s}$ does not seem to be the primary factor limiting $\mathrm{P}_{\mathrm{n}}$ at higher temperatures for any of the studied taxa, an increase in $\mathrm{g}_{\mathrm{s}}$ would typically result in increased transpiration and enhanced evaporative cooling (Burke and Upchurch, 1989). Because river birch is a riparian plant, this species may have evolved with the capacity for increased transpiration under high temperatures, thereby minimizing leaf temperatures. However, Ranney et al. (1991) reported that $\mathrm{g}_{\mathrm{s}}$ of river birch decreased rapidly under very mild water deficit stress, a result suggesting that increased $\mathrm{g}_{\mathrm{s}}$ under high temperatures may only occur under high soil moisture.

Because $\mathrm{P}_{n}$ is a measurement of net $\mathrm{CO}_{2}$ exchange, the response of $\mathrm{P}_{\mathrm{n}}$ to increasing temperatures is strongly influenced by changes in respiration rates. River birch was found to have $a Q_{10}$ value for leaf respiration of 1.37 (Fig. 3), similar to the $Q_{10}$ values that Koike and Sakagami (1985) found for Japanese and monarch birches (over a range of leaf temperatures from 20 to 30C). The greater increase in respiration rates with increasing temperatures for paper birch $\left(Q_{10}=1.78\right)$ most likely contributed to a greater reduction in $\mathrm{P}_{\mathrm{n}}$ for paper birch as temperatures increased. Dark respiration rates have often been found to be higher for plants that are not well adapted to high temperatures (Berry and Raison, 1981; Tieszen and Wieland, 1975). A rapid increase in respiration rates with increasing temperatures could in itself be a limiting factor for heatsensitive plants due to the more rapid exhaustion of carbohydrate reserves (Crawford and Palin, 1981; Lambers, 1985), particularly under high night temperatures (Deal et al., 1990). Increased dark respiration rates can be estimated to reduce $P_{n}$ by 1.1 and 2.5 $\mu \mathrm{mol} \cdot \mathrm{m}^{-2} \cdot \mathrm{s}^{-1}$ for river and paper birch, respectively, over the range of 25 to $40 \mathrm{C}$. However, in this study, $\mathrm{P}_{\mathrm{n}}$ decreased to a greater extent for both taxa, a result indicating that increased dark respiration can only partially explain the inhibition of $\mathrm{P}_{n}$ at higher temperatures.

Chlorophyll fluorescence can serve as an intrinsic probe and sensitive indicator of stress induced limitations to photosynthesis (Bilger et al., 1987; Krause and Weis, 1984; Schreiber and Bilger, 1987). Changes in chlorophyll fluorescence for river and paper birch indicated that photochemical and possibly carboxylation efficiency were compromised at higher temperatures. Slight decreases in $F_{\mathrm{V}}$ and $F_{\mathrm{V}} / F_{\mathrm{M}}$ were observed for paper and river birch at increasing temperatures (Fig. 4). The ratio $F_{\mathrm{v}} / F_{\mathrm{M}}$ has been shown to be proportional to the maximum photochemical yield of PS II (Björkman, 1987; Kitajima and Butler, 1975). A reduction in photochemical yield, as found for paper and river birches at increasing temperatures, may be attributed to a number of factors including inhibition of the water-splitting apparatus (Weis, 1982; Weis and Berry, 1987). The reduction in $F_{\mathrm{v}} / F_{\mathrm{M}}$ indicates reduced photochemical efficiency for both taxa, but does not seem to be responsible for the differential response of $\mathrm{P}_{n}$ at higher temperatures.

Lack of any difference in $q_{\mathrm{P}}$ when compared at 25 and $40 \mathrm{C}$ (Fig. 5 ) indicated there was little effect of these temperatures on electron transport within PS II. These results are consistent with other research results showing that electron transport of temperate plants is typically not affected by temperatures <40C (Weis, 1981). Increased $q_{\mathrm{N}}$ at increasing temperatures, as was found for paper birch, has been attributed to an increase in non-radiative de-excitation (Krause and Weis, 1984). Such an increase in $q_{\mathrm{N}}$ can reflect reduced activity of the Calvin cycle leading to reduced ATP consumption and accumulation of energy in proton gradients across the thylakoid membrane (Schreiber and Bilger, 1987). Other studies have shown that high temperatures $(>20 \mathrm{C})$ can interfere with the Calvin cycle due to reduced activation of RuBP-carboxylase (Weis, 1981). Quenching of dark-level fluorescence, $q_{0}$, observed for both taxa (Fig. 5B), may further suggest that there was some shift in energy distribution in favor of PS I, also resulting in reduced photosynthetic yield. Increases in $q_{0}$ have been attributed to a decrease in absorbed energy directed to PS II due to state 1 to state 2 shifts resulting from transformational changes in the light-harvesting complex (Bilger and Schreiber, 1986; Krause and Weis, 1984; Weis, 1984). Although such a transformation could limit net photosynthesis, it has been suggested that a state 1 to state 2 shift could be a protective mechanism to avoid photodamage to PS II by high light irradiance, which often accompanies heat stress (Havaux and Lannoye, 1987).

Minimal, dark-acclimated fluorescence $\left(F_{0}\right)$ is typically not influenced substantially at increasing temperatures until a threshold, $\mathrm{T}_{\mathrm{C}}$, is reached, at which there is a sudden rise in $F_{0}$ (Fig. 6) (Schreiber and Berry, 1977). The point of inflection has been correlated with critical temperatures resulting in damage to chloroplast envelope membranes and tissue necrosis (Bilger et al., 1984; McCain et al., 1989). Although a gradual increase in $F_{0}$ was found at temperatures $\angle 40 \mathrm{C}$, the increase was slight and was most likely unrelated to observed reductions in $\mathrm{P}_{\mathrm{n}}$. Further, $\mathrm{T}_{\mathrm{C}}$ was $\approx 49 \mathrm{C}$ for both taxa, a result indicating the threshold for thermal injury was similar for both taxa.

Conclusion. The five taxa studied varied in their capacity to maintain photosynthesis as temperatures increased from 25 to $40 \mathrm{C}$, with river birch showing the greatest tolerance and paper birch being the most sensitive. Further study of river and paper birches indicated that the inhibition of $\mathrm{P}_{\mathrm{n}}$ at high temperatures and the differential sensitivity between taxa resulted from several 
factors. These data indicated that inhibition of $\mathrm{P}_{\mathrm{n}}$ at higher temperatures was due largely to nonstomatal limitation for both taxa. Increases in respiration rates, decreases in maximal photochemical efficiency of PS II $\left(F_{\mathrm{v}} / F_{\mathrm{M}}\right)$, and reductions in light energy directed to PS II were apparent for both taxa. The capacity of river birch to maintain greater $P_{n}$ at higher temperatures seemed to result from a lower $\mathrm{Q}_{10}$ for dark respiration and possibly greater thermotolerance of the Calvin cycle, as indicated by lack of nonphotochemical fluorescence quenching with increasing temperatures.

\section{Literature Cited}

Ashburner, K. and T. Schilling. 1985. Betula utilis and its varieties. The Plantsman 7:116-125.

Berry, J. and O. Björkman. 1980. Photosynthetic response and adaptation to temperature in higher plants. Annu. Rev. Plant Physiol. 31:491-543.

Berry, J.A. and J.K. Raison. 1981. Responses of macrophytes to temperature. Encyclopedia Plant Physiol. 12A:278-338.

Bilger, W. and U. Schreiber. 1986. Energy-dependent quenching of dark-level chlorophyll fluorescence in intact leaves. Photosyn. Res. 10:303-308.

Bilger, W., U. Schreiber, and O.L. Lange. 1984. Determination of leaf heat resistance: Comparative investigation of chlorophyll fluorescence changes and tissue necrosis methods. Oecologia 63:256-262.

Bilger, W., U. Schreiber, and O.L. Lange. 1987. Chlorophyll fluorescence as an indicator of heat induced limitation of photosynthesis in Arbutus unedo L., p. 391-399. In: J.D. Tenhunen, F.M. Catarino, O.L. Lange, and W.C. Oechel (eds.). Plant response to stress: Functional analysis in Mediterranean ecosystems. Springer-Verlag, New York.

Björkman, O. 1987. Low-temperature chlorophyll fluorescence in leaves and its relationship to photon yield of photosynthesis in photoinhibition, p. 123-144. In: D.J. Kyle, C.B. Osmond, and C.J. Arntzen (eds.). Photoinhibition. Elsevier, New York.

Björkman, O., M.R. Dadger, and P.A. Armond. 1980. Response and adaptation to high temperatures, p. 233-249. In: N.C. Turner and P.J. Kramer (eds.). Adaptation of plants to water and high temperature stress. Wiley, New York.

Burke, J.J. and D.R. Upchurch. 1989. Leaf temperature and transpirational control in cotton. Environ. Expt. Bot. 29:487-492.

Crawford, R.M.M. and M.A. Palin. 1981. Root respiration and temperature limits to the north-south distribution of four perennial maritime plants. Flora 171:338-354.

Deal, D.L., J.C. Raulston, and L.E. Hinesley. 1990. Leaf color retention, dark respiration, and growth of red-leafed Japanese maples under high night temperatures. J. Amer. Soc. Hort. Sci. 115:135-140.

Even-Chen, Z., S.A. Weinbaum, and R.W. Pearcy. 1981. High temperature effects on leaf resistance, leaf water potential, and photosynthesis of non-bearing prune trees. J. Amer. Soc. Hort. Sci. 106:216-219.

Fitter, A.H. and R.K.M. Hay. 1987. Environmental physiology of plants. 2nd ed. Academic Press, London.

Fryer, J.H. and F.T. Ledig. 1972. Microevolution of the photosynthetic temperature optimum in relation to the elevational complex gradient. Can. J. Bot. 50:1231-1235.

Hällgren, J., E. Sundbom, and M. Strand. 1982. Photosynthetic responses to low temperature in Betula pubescens and Betula tortosa. Physiol. Plant. 54:275-282.

Harlow, W.M., E.S. Harrar, and F.M. White. 1979. Textbook of dendrology. 6th ed. McGraw-Hill, New York.

Havaux, M. and R. Lannoye. 1987. Reversible effects of moderately elevated temperature on the distribution of excitation energy between the two photosystems of photosynthesis in intact avocado leaves. Photosyn. Res. 14:147-158.

Havaux, M., M. Ernez, and R. Lannoye. 1988. Tolerance of poplar (Populus sp.) to environmental stress. I. Comparative study of poplar clones using the in vivo chlorophyll fluorescence method. Acta Ecologia/ Ecologia Plant. 9:161-172

Hetherington, S.E., R.M. Smillie, P. Malagamba, and Z. Huaman. 1983. Heat tolerance and cold tolerance of cultivated potatoes measured by the chlorophyll-fluorescence method. Planta 159:119-124.
Kitajima, M. and W.L. Butler. 1975. Quenching of chlorophyll fluorescence and primary photochemistry in chloroplasts by dibromothymoquinone. Biochemica Biophysica Acta 376:105-115.

Koike, T. and Y. Sakagami. 1985. Comparison of the photosynthetic responses to temperature and light of Betula maximowicziana and Betula platyphylla var. japonica. Can. J. For. Res. 15:631-635.

Krause, G.H. and E. Weis. 1984. Chlorophyll fluorescence as a tool in plant physiology. II. Interpretation of fluorescence signals. Photosyn. Res. 5:193-157.

Krüssman, G. 1984. Manual of cultivated broad-leaved trees and shrubs. vol. 1. Timber Press, Beaverton, Ore.

Lambers, H. 1985. Respiration in intact plants and tissues: Its regulation and dependence on environmental factors, metabolism, and invaded organisms. Encyclopedia Plant Physiol. new series. 18:418-473.

Larcher, W. 1991. Physiological plant ecology. 2nd ed. Springer-Verlag, Berlin.

Liberty Hyde Bailey Hortorium. 1976. Hortus third: A concise dictionary of plants cultivated in the United States and Canada. 3rd ed. Macmillan, New York.

McCain, D.C., J. Croxdale, and J.L. Markley. 1989. Thermal damage to chloroplast envelope membranes. Plant Physiol. 90:606-609.

Moffatt, J.M., R.G. Sears, and G.M. Paulsen. 1990. Wheat high temperature tolerance during reproductive growth. I. Evaluation by chlorophyll fluorescence. Crop Sci. 30:881-885.

Pearcy, R.W. 1977. Acclimation of photosynthetic and respiratory carbon dioxide exchange to growth temperature in Atriplex lentiformis (Torr.) Wats. Plant Physiol. 59:795-799.

Pisek, A., W. Larcher, A. Vegis, and K. Napp-Zinn. 1973. The normal temperature range, p. 102-194. In: H. Precht, J. Christopherson, H. Hensel, and W. Larcher (eds.). Temperature and life. Springer-Verlag, Berlin.

Ranney, T.G., R.E. Bir, and W.A. Skroch. 1991. Comparative drought resistance among six species of birch (Betula): Influence of mild water stress on water relations and leaf gas exchange. Tree Physiol. 8:351-360.

Schreiber, U. and J.A. Berry. 1977. Heat-induced changes of chlorophyll fluorescence in intact leaves correlated with damage of the photosynthetic apparatus. Planta 136:233-238.

Schreiber, U. and W. Bilger. 1987. Rapid assessment of stress effects on plant leaves by chlorophyll fluorescence measurements, p. 27-53. In: J.D. Tenhunen, F.M. Catarino, O.L. Lange, and W.C. Oechel (eds.). Plant response to stress: Functional analysis in Mediterranean ecosystems. Springer-Verlag, New York.

Schulze, E.D., O.L. Lange, M. Evenari, L. Kappen, and U. Buschbom. 1974. The role of air humidity and leaf temperature in controlling stomatal resistance of Prunus armeniaca L. under desert conditions. Oecologia 17:159-170.

Tesfai, M., J.W. Hanover, D.R. Layne, and J.A. Flore. 1991. Leaf temperature effects on net photosynthesis, dark respiration, and photorespiration of seedlings of black locust families with contrasting growth rates. Can. J. For. Res. 21:1616--1621.

Tieszen, L.L and N.K. Wieland. 1975. Physiological ecology of arctic and alpine photosynthesis and respiration, p. 157-200. In: F.J. Vernberg (ed.). Physiological adaptation to the environment. Intext Educational Publ., New York.

van Kooten, O. and J.F.H. Snel. 1990. The use of chlorophyll fluorescence nomenclature in plant stress physiology. Photosyn. Res. 25:147-150.

von Caemmerer, S. and G.D. Farquhar. 1981. Some relationships between the biochemistry of photosynthesis and the gas exchange of leaves. Planta 153:376-387.

Weis, E. 1981. Reversible heat-inactivation of the Calvin cycle: A possible mechanism of the temperature regulation of photosynthesis. Planta 151:33-39.

Weis, E. 1982. Influence of light on the heat sensitivity of the photosynthetic apparatus in isolated spinach chloroplasts. Plant Physiol. 70:1530 1534.

Weis, E. 1984. Short term acclimation of spinach to high temperatures. Plant Physiol. 74:402-407.

Weis, E. and J.A. Berry. 1987. Quantum efficiency of photosystem II in relation to 'energy'-dependent quenching of chlorophyll fluorescence. Biochemica Biophysica Acta 894:198-208. 